\title{
The sex ratio in spina bifida
}

\author{
WILLIAM H. JAMES
}

From the Galton Laboratory, University College London, Wolfson House, London NW1 2HE

SUMMARY Published reports on the sex ratio of spina bifida have been reviewed. With one exception, there seems to be no evidence of variation in the sex ratio of spina bifida. In particular, unlike anencephaly, the sex ratio of spina bifida seems to be unrelated to the prevalence of the malformation: this $(M /(M+F))$ is of the order of 0.44 in respect of all spina bifida births (liveborn and still- $\mathrm{G}$ born). The sex ratio of spina bifida in Negroes does not seem to differ from that in whites (thoughiw the data on this point are not numerous). The exception noted above concerns spina bifida occurring in twins: these cases are disproportionately often female. The point stands in need of explanation. .5

There is considerable variation in the rates of anencephaly and of spina bifida. In this country, much of this variation seems to be environmental in origin, being associated with such variables as social class and season. In general, the rates of the two malformations vary in unison with these variables. For instance, in regard to UK data for 1958, Butler and Alberman (1970) found that the rates of both malformations at birth in social classes 4 and 5 were at least double the rates in classes 1 and 2 . Rogers and Weatherall (1976) reported that for England and Wales 1964-1972, the two malformations had roughly equal amplitudes of seasonal variation, the month of highest risk having a rate about $15 \%$ higher than the month of lowest risk. Rogers and Weatherall (1976) also reported regional variations in the two malformations with maximum risks for both in Wales, and minimum risks in East Anglia: the range of risk was about two-fold for both malformations.

The two malformations have shown parallel secular trends in Dublin 1900-1965 (Elwood, 1973), in Berlin after the second world war (Lenz, 1965), in New York State 1945-1971 (Janerich, 1973), in Birmingham 1942-1949 (MacMahon et al., 1951), and in Boston 1930-1965 (Naggan, 1969).

Furthermore, it is well established that cases of anencephaly and spina bifida tend to recur within the same sibships (Carter et al., 1968; Smithells et al., 1968), so the evidence is overwhelming that the two malformations share some cause(s).

It has been shown that the sex ratio of anencephalics correlates with the prevalence at birth of anencephaly both across populations (Knox, 1974)

Received for publication 29 December 1978 and within populations (James, 1979). It therefore응 seemed worth reviewing published reports to see whether this feature of anencephaly was alsoce characteristic of spina bifida.

\section{Materials and methods}

The sex ratio of spina bifida may be estimated from four different sorts of material: (1) data from studieso which ascertain all affected cases in a specified $\overrightarrow{\overrightarrow{0}}$ population; (2) data from cases which have been 3 born alive (for example, birth certificates, death? certificates, or records of infant mortality); (3) data? from cases which were stillborn; and (4) hospital records. It is important to separate these variouso sorts of data because of a source of bias in estimating the spina bifida sex ratio. As in anencephaly, the sex. ratio (proportion of males) of liveborn spina bifidaO cases is higher than the sex ratio of stillborn cases: in other words, female cases are less likely to be borno alive (Record and McKeown, 1949). Therefore, $>$ studies which are based on liveborn cases (and which․ㅡ. thus fail to take account of stillborn cases) aren likely to yield overestimates of the sex ratio of alp cases. Similarly, studies based on stillborn cases $N$ tend to underestimate this sex ratio. It is not known $\mathrm{N}$ that estimates based on hospital records are subjecto to bias, because it is not clear that the same propore tion of stillborn and liveborn cases would be bornष in hospital. However, the possibility exists, so data ${ }^{\text {? }}$ of this sort have been kept separate.

The Tables give data from selected studies: the only basis for selection has been to limit the review to reasonably large samples. 
Results

VARIATION OF SEX RATIO ACROSS SAMPLES It seems that the best data for testing this variability are those in Table 1. In this Table, the values are arranged in order of the estimated prevalence rates. Visual inspection suggests that there is no correlation between these rates and the corresponding sex ratios, and this judgment is confirmed by the fact that the $\chi_{16}^{2}$ across the two columns of male and female frequencies takes the value $7 \cdot 82, \mathrm{P} \bumpeq 0 \cdot 9$. Thus, there is no indication in these data that the sex ratio of spina bifida varies from one sample to another, even less with the prevalence rates. (It should be noted that all the samples in Table 1 are mutually exclusive.)

Table 2 gives the sexes of the hospital births. There is no significant variation between the sex ratios in the various samples in this Table $\left(\chi^{2}=1 \cdot 50\right.$, df 3 , $0 \cdot 7>P>0.6$ ), and there is no significant difference between the overall sex ratio in this Table and that in Table $1\left(\chi^{2}=0.8\right.$, df $\left.1,0.4>P>0 \cdot 3\right)$.

Table 3 gives data on liveborn cases. There is significant variation between the sex ratios in this Table $\left(\chi^{2}=28 \cdot 90\right.$, df $\left.9, \mathrm{P}<0.001\right)$, and the overall sex ratio in this Table is significantly different from that in Table $1\left(\chi^{2}=7 \cdot 54\right.$, df $\left.1, P \bumpeq 0.005\right)$.

The difference between the overall sex ratios in Tables 1 and 3 may reasonably be ascribed to the fact that female cases are more likely to be stillborn than male cases.

The only Table containing variation of sex ratio between samples is Table 3 . It seems likely that part
Table 2 Numbers of male and female spina bifida cases ascertained through hospital records

\begin{tabular}{lccl}
\hline Authors & Males & Females & $\begin{array}{l}\text { Sex ratio } \\
(\% \text { male })\end{array}$ \\
\hline Stevenson et al. (1966) & 161 & 192 & 46 \\
MacMahon et al. (1953) & 175 & 208 & 46 \\
Collmann and Stoller (1962) & 43 & 45 & 49 \\
Book (1951) & 16 & 27 & 37 \\
& $\leqslant 395$ & 472 & 46 \\
\hline
\end{tabular}

The data of Stevenson et al. (1966) were collected from 24 different reporting centres around the world. There is no evidence for heterogeneity (as tested by a $\chi^{2}$ analysis) between the sex ratios of spina bifida reported by these different centres.

of this variation is the result of a variable level of selection when cases are chosen to be treated. Females are, in general, more severely affected than males, so (to varying degrees) they would be selected against in the decision to refer for surgery. Another possible cause of the variation in this Table is that variable health standards might be expected to alter the proportions of the severely affected (predominantly female) cases which are liveborn rather than stillborn. Lastly, since among the liveborn cases females are more severely affected than males, it follows that the subsequent 'deaths' (ascribed to the malformation) would be expected to contain a high proportion of females, because some of the survivors (mostly males) would escape from such records altogether to die eventually of some unrelated cause. Therefore, death certificates would be expected to contain a higher proportion of females than birth notifications.

Table 1 Numbers of male and female spina bifida cases ascertained in population studies

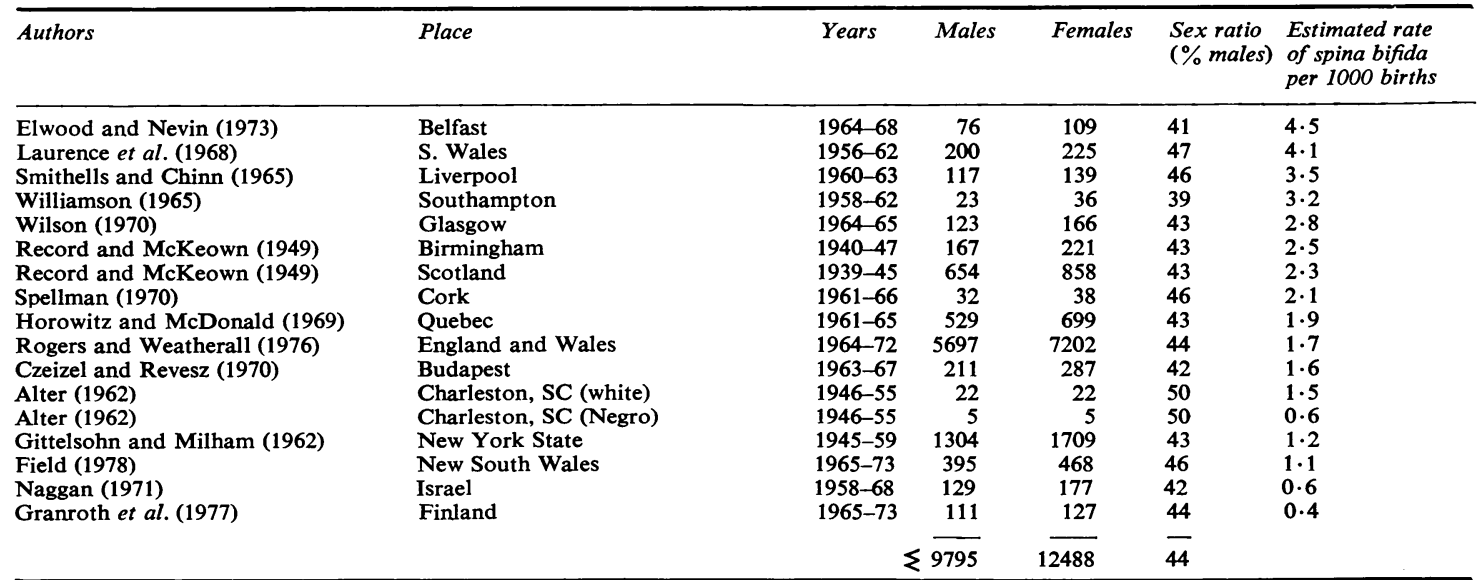

(1) In addition to the population studies cited in the Table, two other authors seem to have obtained representative samples of spina bifida (liveborn and stillborn) without estimating the numbers of related normal births. These were Polman (1951), who ascertained 22 males and 24 females (48\% males) in Groningen and Drenthe (Holland), and Timson (1969), who ascertained 25 males and 34 females (42\% males) in Manchester and district.

(2) Data from Butler and Alberman (1970), in respect of England, Wales, and Scotland for March, April, and May 1958, and from Carter and Evans (1973), in respect of Greater London 1965-1968, are not included in Table 1 because some of these data are already included in the Table. 
Table 3 Numbers of male and female cases of liveborn spina bifida

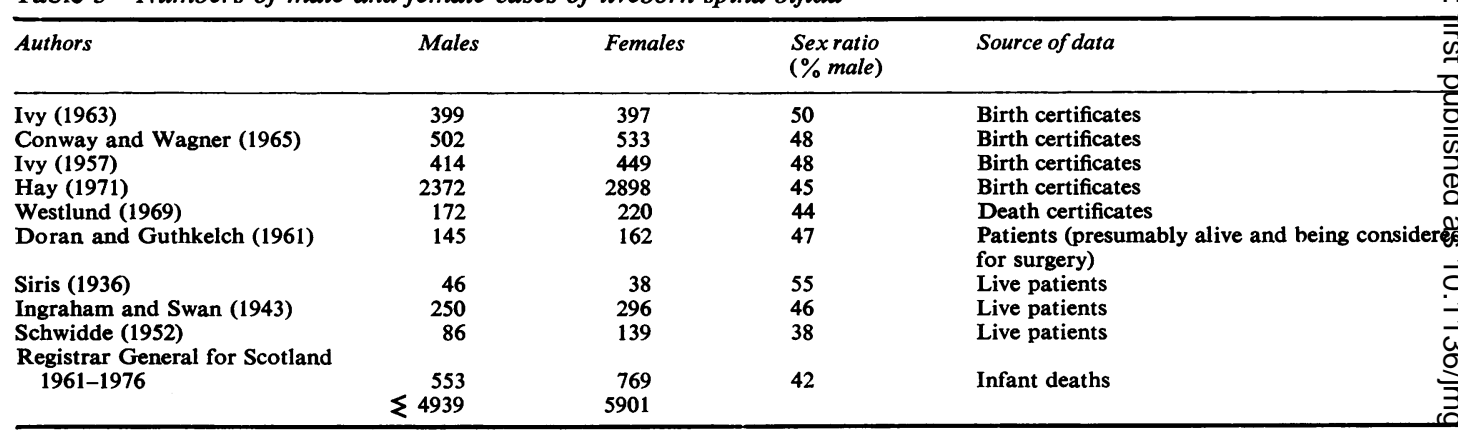

VARIATION OF SEX RATIO WITHIN SAMPLES

Tables $4 a, b$, and $c$ give the sexes of the stillborn cases reported in Scotland 1961-1976. The overall sex ratio of these cases is significantly different from those in Table $1\left(\chi^{2}=5 \cdot 3, P \bumpeq 0 \cdot 02\right)$, but there are no detectable trends of sex ratio within these Tables. Table 4d gives the infant deaths (deaths in the first year) attributed to spina bifida in Scotland 19611976. It will be seen that even within this substantial sample, there is no discernible trend of sex ratio with social class.

Table 4a Numbers of male and female spina bifida stillbirths by social class, Scotland 1961-1976

\begin{tabular}{lcccccc}
\hline & \multicolumn{3}{c}{ Social class } & & & \\
& \multicolumn{1}{c}{1} & 2 & 3 & 4 & 5 & Total \\
\hline Male & 4 & 12 & 82 & 26 & 26 & 150 \\
Female & 11 & 16 & 146 & 48 & 32 & 253 \\
Sex ratio & 27 & 43 & 36 & 35 & 45 & 37 \\
(\% males) & & & & & & \\
\hline
\end{tabular}

Table 4b Numbers of male and female spina bifida stillbirths by maternal age, Scotland 1961-1976

\begin{tabular}{llllllll}
\hline & \multicolumn{9}{c}{ Maternal age } \\
& $<20$ & $20-24$ & $25-29$ & $30-34$ & $35-39$ & $40+$ & Total \\
\hline Male & 25 & 57 & 44 & 22 & 13 & 4 & 165 \\
Female & 31 & 81 & 83 & 34 & 28 & 9 & 266 \\
Sex ratio & 45 & 41 & 35 & 39 & 32 & 31 & 38 \\
(\% males) & & & & & & & \\
\hline
\end{tabular}

Table 4c Numbers of male and female spina bifida stillbirths by parity, Scotland 1961-1976

\begin{tabular}{lrlllll}
\hline & Parity & & & & & \\
& 0 & 1 & 2 & 3 & $4+$ & Total \\
\hline Male & 63 & 33 & 27 & 16 & 11 & 150 \\
Female & 106 & 55 & 36 & 29 & 26 & 252 \\
Sex ratio & 37 & 37 & 43 & 36 & 30 & 37 \\
(\% males) & & & & & & \\
\hline
\end{tabular}

Table 4d Infant deaths attributed to spina bifida by sex and social class, Scotland 1961-1976

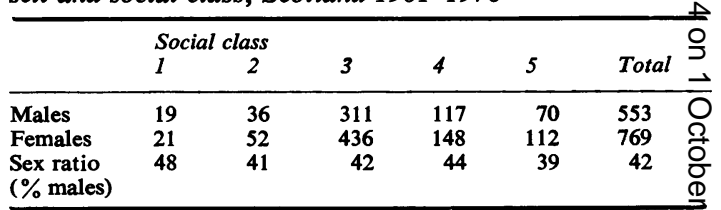

(1) When the data in this Table are pooled with those in Table (thus comprising most of the spina bifida cases born in Scotland 1961-1976), the sex ratios (\% males) of the cases born in social classes $1,2,3,4$, and 5 are $42,41,40,42$, and 40 .

(2) The overall sex ratio in this Table $(41 \%)$ is lower than that Table 1: this is presumably because Table $4 \mathrm{~d}$ includes no case wh survived for more than one year after birth.

(3) The Registrar General for Scotland seems not to publish data $\overline{\text { An }}$ infant deaths by cause, sex, maternal age, or parity, so Tables $4 \mathrm{~b}$ an cannot be augmented in this way with infant deaths.

\section{VARIATION OF SEX RATIO BY RACE AND}

\section{TWINNING}

The failure to find variation in the sex ratio of spirt bifida raises the question of whether this sex ratio varies with any variable. Accordingly, data wege reviewed in regard to race and twinning.

\section{Race}

Hewitt (1965) suggested, without offering supporting data, that spina bifida in Negroes has a 'distincty masculine sex ratio' in contrast to that in white? Table 5 summarises all the data $I$ have been able

Table 5 Numbers of male and female Negro cases of $N$ spina bifida

\begin{tabular}{|c|c|c|c|}
\hline Authors & Males & Females & $\begin{array}{l}\text { Sex ratioర } \\
(\% \text { males }\end{array}$ \\
\hline $\begin{array}{l}\text { Gittelsohn and Milham (1962) } \\
\text { Alter (1962) } \\
\text { Stevenson et al. (1966) }\end{array}$ & $\begin{array}{r}17 \\
5 \\
9 \\
<31\end{array}$ & $\begin{array}{r}25 \\
5 \\
2 \\
32\end{array}$ & $\begin{array}{l}40 \\
50 \\
82 \\
49\end{array}$ \\
\hline
\end{tabular}

Table 5 cites Gittelsohn and Milham (1962) who report data in respegt of Upstate New York 1945-1959. Elsewhere (1965), they report की the data for Upstate New York 1950-1960. These latter data give 90 male and 22 female non-white cases of spina bifida. 
locate on the point. There seems no strong evidence here for Hewitt's claim though, admittedly, the data are not numerous.

\section{Twinning}

Lorber and Rogers (in the Table privately circulated in supplement to their 1977 paper) cite data which suggest that, in both same-sexed and oppositesexed twin pairs, the members affected with spina bifida are significantly more likely to be female than are singleton cases.

\section{Comment}

The general failure to find variability in the sex ratio of spina bifida is puzzling, bearing in mind (1) the known variation of the sex ratio of anencephaly with the prevalence of anencephaly, and (2) the strong evidence that the two conditions share a cause or causes.

This lack of variation seems to constitute evidence against the hypothesis of Knox (1974), and it points to the necessity of accounting for the differences between the epidemiologies of anencephaly and spina bifida.

The variation of the sex ratio of anencephaly with its prevalence has led me to speculate (James, 1979) that it has two sorts of cause: (1) an environmental cause which produces predominantly female cases; and (2) another cause (either environmental or genetic) which produces the two sexes in roughly equal numbers.

At first sight, it is tempting to suppose that since the sexes of cases of spina bifida are apparently of roughly equal numbers, spina bifida may be produced by the second of these two causes hypothesised to be responsible for anencephaly. The case against this supposition is that spina bifida, though it may perhaps not be subject to so much environmental variation as anencephaly, certainly does show a great deal of environmental variation. The inference seems to be that some environmental cause produces both anencephalics which are predominantly female, and spina bifida cases of both sexes in roughly equal numbers.

I suggest that the same environmental teratogen acts at slightly different times in gestation to produce these two sorts of effect, very early to produce anencephaly and slightly later to produce spina bifida. The different sex ratios would be accounted for by supposing that: (1) 'delayed' embryos are more susceptible to the teratogen; (2) initially, female zygotes are more ' delayed,' are'formed later, than male zygotes (James, 1976; Roberts, 1978); and (3) zygotes which are initially delayed progressively 'catch up' during the course of gestation.
I am supported by the National Fund for Research into Crippling Diseases.

\section{References}

Alter, M. (1962). Anencephalus, hydrocephalus and spina bifida. Archives of Neurology, 7, 411-422.

Book, J. A. (1951). The incidences of congenital diseases and defects in a South Swedish population. Acta Geneticae et Statisticae Medicae, 2, 289-311.

Butler, N. R., and Alberman, E. D. (1970). Perinatal Problems. Livingstone, London.

Carter, C. O., David, P. A., and Laurence, K. M. (1968). A family study of major CNS malformations in South Wales. Journal of Medical Genetics, 5, 81-106.

Carter, C. O., and Evans, K. (1973). Spina bifida and anencephalus in Greater London. Journal of Medical Genetics, 10, 209-234.

Collmann, R. D., and Stoller, A. (1962). Epidemiology of congenital anomalies of the CNS with special reference to patterns in the state of Victoria, Australia. Journal of Mental Deficiency Research, 6, 22-37.

Conway, H., and Wagner, K. J. (1965). Congenital anomalies of the head and neck as reported on birth certificates in New York City 1952-62. Plastic and Reconstructive Surgery, 36, 71-79.

Czeizel, A., and Revesz, C. (1970). Major malformations of the CNS in Hungary. British Journal of Preventive and Social Medicine, 24, 205-222.

Doran, P. A., and Guthkelch, A. N. (1961). Studies in spina bifida cystica. Journal of Neurology, Neurosurgery and Psychiatry, 24, 331-345.

Elwood, J. H. (1973). Epidemics of anencephalus and spina bifida in Ireland since 1900. International Journal of Epidemiology, 2, 171-175.

Elwood, J. H., and Nevin, N. C. (1973). Factors associated with anencephalus and spina bifida in Belfast. British Journal of Preventive and Social Medicine, 27, 73-80.

Field, B. (1978). Neural tube defects in New South Wales, Australia. Journal of Medical Genetics, 15, 329-338.

Gittelsohn, A. M., and Milham, S. (1962). Declining incidence of CNS anomalies in New York State. British Journal of Preventive and Social Medicine, 16, 153-158.

Gittelsohn, A. M., and Milham, S. (1965). Vital record incidence of congenital malformations in New York State. In Genetics and the Epidemiology of Chronic Diseases, ed J. V. Neel, M. W. Shaw, and W. J. Schull. US Department of Health, Education and Welfare, PHS Publication No 1163 , Washington DC.

Granroth, G., Hakama, M., and Saxen, L. (1977). Defects of the CNS in Finland. I. Variations in time and space, sex distribution and parental age. British Journal of Preventive and Social Medicine, 31, 164-170.

Hay, S. (1971). Sex differences in the incidence of certain congenital malformations: a review of the literature and some new data. Teratology, 4, 277-286.

Hewitt, D. (1965). Regional variations in the incidence of spina bifida. In Genetics and the Epidemiology of Chronic Diseases, ed J. V. Neel, M. W. Shaw, and W. J. Schull. US Department of Health, Education and Welfare, PHS Publication No. 1163, Washington DC.

Horowitz, I. and McDonald, A. D. (1969). Anencephaly and spina bifida in the province of Quebec. Canadian Medical Association Journal, 100, 748-755.

Ingraham, F. D., and Swan, H. (1943). Spina bifida and cranium bifidum (encephalocele): survey of 546 cases. New England Journal of Medicine, 228, 559-563.

Ivy, R. H. (1957). Congenital anomalies as recorded on birth certificates in the Division of Vital Statistics of the 
Pennsylvania Department of Health 1951-55. Plastic and Reconstructive Surgery, 20, 400-411.

Ivy, R. H. (1963). Congenital anomalies as recorded on birth certificates in the Division of Vital Statistics of the Pennsylvania Department of Health 1956-60. Plastic and Reconstructive Surgery, 32, 361-367.

James, W. H. (1976). Timing of fertilization and sex ratio of offspring-a review. Annals of Human Biology, 3, 549-556.

James, W. H. (1979). The sex ratio in anencephaly. Journal of Medical Genetics, 16, 129-133.

Janerich, D. T. (1973). Epidemic waves in the prevalence of anencephaly and spina bifida in New York State. Teratology, 8, 253-256.

Knox, E. G. (1974). Twins and neural tube defects. British Journal of Preventive and Social Medicine, 28, 73-80.

Laurence, K. M., Carter, C. O., and David, P. A. (1968). Major CNS system malformations in South Wales. 2. Pregnancy factors, seasonal variation and social class effects. British Journal of Preventive and Social Medicine, 22, 212-222.

Lenz, W. (1965). Epidemiology of congenital malformations. Annals of the New York Academy of Sciences, 123, 228-236.

Lorber, J., and Rogers, S. C. (1977). Spina bifida cystica and anencephalus in twins. Zeitschrift für Kinderchirurgie und Grenzgebiete, 22, 565-571.

MacMahon, B., Pugh, T. F., and Ingalls, T. H. (1953). Anencephalus, spina bifida and hydrocephalus: incidence related to sex, race and season of birth and incidence in siblings. British Journal of Preventive and Social Medicine, 7, 211-219.

MacMahon, B., Record, R. G., and McKeown, T. (1951). Secular changes in the incidence of malformations of the CNS. British Journal of Social Medicine, 5, 254-258.

Naggan, L. (1969). The recent decline in prevalence of anencephaly and spina bifida. American Journal of Epidemiology, 89, 154-160.

Naggan, L. (1971). Anencephaly and spina bifida in Israel. Pediatrics, 47, 577-586.

Polman, A. (1951). Anencephaly, spina bifida and hydrocephaly. Genetica, 25, 29-78.

Record, R. G., and McKeown, T. (1949). Congenital malformations of the CNS. British Journal of Social Medicine, 3, 183-219.

Roberts, A. M. (1978). The origins of fluctuations in the human secondary sex ratio. Journal of Biosocial Science, 10, 169-182.

Rogers, S. C., and Weatherall, J. A. C. (1976). Anencephalus, Spina Bifida and Congenital Hydrocephalus: England and Wales 1964-72. Studies on Medical and Population Subjects No 32. Office of Population Censuses and Surveys. HMSO, London.

Schwidde, J. T. (1952). Spina bifida: survey of 225 encephaloceles, meningoceles and myelomeningoceles. American Journal of Diseases of Children, 84, 35-51.

Siris, I. E. (1936). Spina bifida: treatment and analysis of 84 cases. Annals of Surgery, 103, 97-123.
Smithells, R. W., and Chinn, E. R. (1965). Spina bifida in Liverpool. Developmental Medicine and Child Neurology 7, 258-268.

Smithells, R. W., D'Arcy, E. E., and McAllister, E. F. (1968)음 The outcome of pregnancies before and after the birth of infants with nervous system malformations. Developmenta? Medicine and Child Neurology, Suppl. 15, 6-10.

Spellman, M. P. (1970). A 5-year survey in Cork of spina吕 bifida and hydrocephaly. Journal of the Irish Medica Association, 63, 339-342.

Stevenson, A. C., Johnston, H. A., Stewart, M. I. P., and Golding, D. R. (1966). Congenital malformations. A report of a study of series of consecutive births in 24 centres. Bulletin of the World Health Organization, 34, Suppl. 9. Basic Tabulations. Medical Research Council of Great Britain.

Timson, J. (1969). The sex ratio in spina bifida. Genetica: 40, 427-433.

Westlund, K. (1969). Mortality from congenital malforci mations of the CNS in Norway 1951-65. British Journal of w Preventive and Social Medicine, 23, 28-33.

Williamson, E. M. (1965). Incidence and family aggregationo of major congenital malformations of the CNS. Journal of Medical Genetics, 2, 161-172.

Wilson, T. S. (1970). Congenital malformations of the CNS among Glasgow births 1964-68. Health Bulletin (Edin burgh), 28, 32-38.

Requests for reprints to Dr W. H. James, Depart $\vec{\oplus}$ ment of Human Genetics and Biometry, The Galton ${ }^{6}$ Laboratory, University College London, Wolfsorb House, 4 Stephenson Way, London NW1 2HE.

\section{Note added in proof}

Since this paper was prepared, data on a large sample of liveborn Negro spina bifida cases have been published (Taffel, 1978). When these are pooled with the data cited above, there are 131 male and 109. female Negro spina bifida cases. Tested against a sex ratio of 0.46 (as suggested for liveborn cases in Table 3 above), these data yield a $\chi^{2}$ of $7 \cdot 123$ $\mathbf{P}<0.01$. So it seems that Negro cases are dis. proportionately often male.

\section{Reference}

Taffel, S. (1978). Congenital Anomalies and Birth Injurie Among Live Births: United States, 1973-74. Vital and Healthe. Statistics, Series 21, Number 31. US Department of HealthN Education and Welfare, Hyattsville, Maryland. 